\title{
Mobilizing and engaging your community to reduce victimization and reinvest police resources
}

\author{
J.V.N. (Vince) Hawkes*
}

\begin{abstract}
The Ontario government released its most recent Ontario Mobilization \& Engagement Model for Community Policing (OMEM) in 2010, but many police services in the province are just now starting to move toward implementation. OMEM emphasizes having all community members and human services agencies working with the police to keep neighbourhoods safer, more secure, and healthier. The most appropriate service takes the lead in any community safety and wellbeing initiative. The new model requires considerable cultural change from all participants to be successful. This article outlines the Ontario Provincial Police efforts to implement OMEM and some of its early successes and ongoing challenges.
\end{abstract}

Key Words Ontario Mobilization \& Engagement Strategy (OMEM), social disorder, community engagement, public safety, policing, situation table, risk-driven collaboration

Journal of CSWB. 2016 Aug; 1(2):21-25

www.journalcswb.ca

\section{INTRODUCTION}

The Ontario Provincial Police (OPP) is in the midst of an ambitious modernization program to profoundly change the way it delivers services: it enthusiastically adopted the Ontario Mobilization \& Engagement Model for Community Policing (OMEM) in 2010 (OACP, 2016) and is working towards bringing about the necessary complete cultural change to be successful.

It is too early for the OPP to highlight any major accomplishments, but a look at its efforts and small successes to this point will be instructive for any police or community service that is also looking to use OMEM outcomes to reduce victimization and improve community safety.

\section{ENGAGEMENT, EDUCATION AND ENFORCEMENT}

OMEM represents a philosophy and a concept focused on increasing community safety in partnership with the community by reducing crime, victimization, and social disorder. The OPP is committed to Engagement, Education and Enforcement, the three pillars that support this philosophy when addressing the root causes of crime and social disorder.

OMEM emphasizes having all community members working with police to make and keep neighbourhoods safer, more secure, and healthier. Under the new model, initiatives are led by the most appropriate agency, which may actually not be the police. The model empowers officers to include community partners to support or address the underlying "risk" or "social disorder" factors. The previous Ontario model from 1996 was geared more toward police leaders and less toward multi-sector frontline practitioners.

This new model outlines roles, responsibilities, and approaches for police and community partners to use in a variety of communities ranging from very safe to very troubled. Where there are threats to safety and security in a community, enforcement clearly rests with the police. Where efforts are directed to community mobilization and community safety, police may more typically motivate and support community members and other agencies to engage in programs and initiatives, ultimately looking to these members to assume a leadership role. The model is structured to direct the community's safety and well-being efforts, based on analysis, toward addressing whatever type of crime or social disorder affects the community. The OPP considers OMEM an opportunity to build capacity and build relationships that support one another (Figure 1).

In a time when the rising cost of policing is part of a national discussion, it is not surprising that the conversation often begins focused on dollars and cents and the response to non-traditional police calls for service (CFS). The collection and parameters for police response statistics vary greatly across Ontario and Canada, but there is a general perception that social disorder CFS are increasing. 


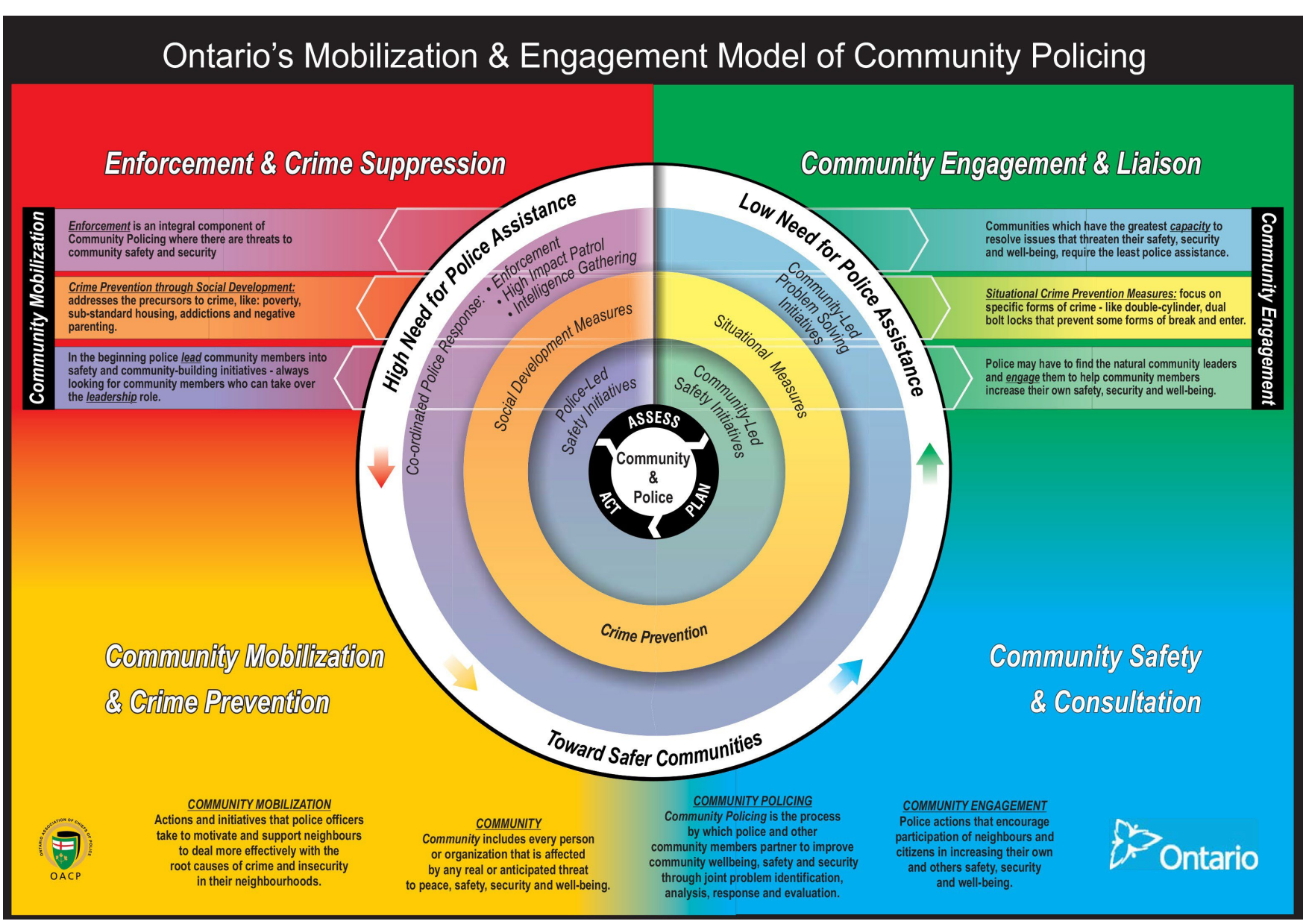

FIGURE 1 The graphic representation of OMEM was purposely designed to resemble the Ontario Use of Force Model which is very familiar to officers.

The Canadian Association of Chiefs of Police has defined social disorder in the following way: "A condition in which the behaviour and activities of people within a specific location lack sufficient control or order, deviating significantly from what would be considered by most to be comfortable, reasonable or safe" (CACP, 2016). These are occurrences which can include, but are not limited to: emotionally disturbed people; people affected by mental health issues or experiencing a mental health crisis; domestic strife; people with addictions; and people disengaged from their community, such as homeless youth. These social disorder situations often involve the police, but do not necessarily result in criminal charges.

Currently, when it comes to social disorder, police officers often do not have access to the tools and skills best suited to truly address the risks presenting. OMEM aims for better outcomes for communities by encouraging everyone, including police and other service agencies (such as child welfare, housing, and mental health, to name a few) to work together for better responses. The goal is always to improve outcomes, not to reduce the cost of police and other services, although that might be an encouraging secondary impact. Any resources saved can be reinvested in other high-risk areas.

\section{HOW DO YOU CHANGE A CORPORATE CULTURE?}

In any significant cultural change, internal and external communication is crucial. The OPP's Community Safety Services (CSS), part of the Field Operations Provincial Command, has developed a communication strategy in collaboration with the OPP Corporate Communications and Strategy Management Bureau. Like all good communication strategies, it began by developing consistent messaging, language, and branding of the new model to best communicate the expected cultural change and the values and goals.

The communication strategy reinforced the model in different venues with a goal to build champions. Along with the communication strategy came consistent and on-going follow-up, support, and encouragement. The OPP Commissioner, three Deputy Commissioners, and the civilian Provincial Commander enthusiastically adopted OMEM and set out to model the vision and needed changes for the entire organization.

With over 9,000 officer and civilian members spread out over a province geographically bigger than most countries, encouraging permanent cultural change at the OPP frontline is challenging. The OPP has embedded OMEM principles 
in internal promotion and competitive processes so future leaders will also model the change for all.

The OPP is also tracking proactive community mobilization (participating in targeted enforcement, supporting public safety education, liaising with community partners, and identifying risks and social disorder) through measurement and data collection in its Records Management Systems and Daily Activity Reporting. The message to the frontline is that these are core policing activities and the resulting analytics will help managers encourage necessary behavioural change.

\section{WHAT THE OPP HAS ACCOMPLISHED SO FAR: AWARENESS}

CSS established a Detachment Commander Advisory Group in 2013 to ensure that implementation supports the frontline by recommending, suggesting, and advising on the most effective and appropriate approaches and supports. Without significant buy-in from frontline personnel, any effort to adopt OMEM can be fraught with resistance.

Over 1,035 OPP frontline officers have participated in workshops in all OPP regions, covering: Analytics; Focus Patrol; and Community Mobilization and Engagement. Focus Patrol is one part of the OPP's OMEM efforts aimed at placing officers in the right place at the right time. Using sophisticated crime analytics and tools, such as Global Positioning System locators in patrol cars, the OPP has significantly improved its crime prevention and crime abatement programs.

All five OPP regions and the Highway Safety Division have established Community Safety Committees to coordinate and support Provincial Community Safety initiatives within the OPP's Field Operations. Each committee has a CSS member assigned in a liaison role to share information and to assist in the adoption of OMEM.

The OPP Strategic Plan supports the successful implementation of OMEM. The OPP's work to mobilize and engage for community safety will allow it to reinvest and apply a focused use of resources in service delivery. The OPP has developed an important e-Learning module designed to educate and familiarize OPP members about the principles and practices of community mobilization and collaborating for community safety. This training was launched in January 2015 and is mandatory for all uniform members.

To gauge progress, CSS conducted a random phone survey of frontline members to gauge the level of understanding of OMEM in December 2014 and then again in December 2015 after the rollout of the e-learn training. The survey results indicate that OMEM awareness went from 50 per cent to 100 per cent in the year between the two surveys.

\section{APPLYING OMEM PRINCIPLES}

When seeking complete organizational change, effective management requires testing on a smaller scale where the organization can learn, make adjustments, and then apply any successes and avoid repeating any problems across the entire service. The OPP's Kenora and Bancroft Detachments (see Box. 1) have completed their participation in the Ministry's Safety and Well-Being Planning pilot and will now provide leadership throughout the province in the development of localized, community-driven safety plans. The Amalguin
Highlands and Kirkland Lake Detachments are currently in the midst of additional pilots.

The OPP also completely restructured CSS to support the organizational priorities of community safety and well-being and improve adaptability so it can respond to emerging risks facing Ontario's communities. It retains its current mandate with a focus on both operations and support to the frontline in relation to community safety and well-being.

In December of 2015, the OPP publicly released its Mental Health Strategy: Our People, Our Communities. This major organizational strategy is consistent with the collaborative approaches identified in OMEM and, significantly, views the mental health needs of its members and communities as inseparable (OPP, 2016).

The OPP has also forged a strong participation with The Push for Change, a national awareness and youth empowerment campaign designed to end youth homelessness. To engage communities and illustrate the problems, former heroin-addict-and-street-kid-turned-successful-entrepreneur Joe Roberts will push a grocery cart across Canada in 2016 and 2017. The OPP is mobilizing and engaging with youth and various stakeholders in more than 50 community-based events across Ontario as part of The Push for Change. It will work with community partners, youth, mental health and addictions service providers, and others throughout 2016 and into 2017 to address issues affecting the safety and well-being of OPP-policed communities and Ontario's youth.

By partnering with The Push for Change, the OPP continues to work collaboratively for community safety and wellbeing. This campaign gives the OPP even more opportunities to positively affect the future of Ontario's youth. Again, the message to the frontline is clear: this too is a core policing activity under OMEM.

\section{COLLABORATIVE RESPONSE MODELS: SITUATION TABLES}

Jurisdictions planning a stronger risk mitigation model within the Amber Zone of OMEM (OACP, 2016) should begin with an analysis-based community assessment. Many are finding that the establishment of multi-disciplinary Situation Tables to address areas in which there is acutely elevated risk to individuals, families, groups or locations is an attractive strategy (see Figure 2). The Situation Table participants work collaboratively to mitigate the presenting risks.

Here are some encouraging indications of progress in the development of Situation Tables:

There are currently 48 Situation Tables across the province of Ontario, either established or in planning stages. The OPP has representatives at 26 of those tables.

The OPP participates in a provincial community of practice teleconference group of existing Subject Matter Experts that meets quarterly to discuss best practices and lessons learned at Situation Tables. The group supports the Situation Table Chairpersons in the province. The OPP has also established a complementary community of practice group for its personnel.

The Risk Tracking Database (RTD), which is currently being implemented by the Ministry, will allow for the measurement of situations where risk was reduced 


\section{Box 1. OMEM Successes in Bancroft.}

When a new Detachment Commander, Mark Wolfe, arrived at the OPP's Bancroft Detachment in 2012, he knew little about the Ontario Mobilization \& Engagement Model (OMEM), but quickly realized that the small, isolated, central Ontario community had serious policing problems.

His Regional Commander suggested he pilot an OMEM approach to the problems and put him in touch with a consultant, Dr. Hugh C. Russell. It took a while to figure out how to apply OMEM principles to such an isolated community with limited resources, but they worked it out.

The new Detachment Commander also soon discovered that local municipal leaders were mostly concerned about the costs of policing and they expected him to take complete responsibility for managing those costs. Using analytics, collaboration, relationship building, and communication skills, he eventually convinced the municipal leaders that the entire community was responsible for reducing victimization, which could lead to a reduction in costs. He also made it clear that the police were not going to automatically be the leaders in these efforts.

This required a cultural shift for everyone, including himself and his staff, since most police officers highly value leadership and view themselves as effective leaders.

Here are just two positive, illustrative results of applying OMEM in Bancroft:

Advanced analytics indicated that many of the calls for service (CFS) were property crimes occurring at local businesses such as shoplifting, fraud, and other forms of theft, often related to the local drug trade. The Detachment Commander built relationships with local business owners and talked to them about steps they could take to reduce their victimization. He also revised his patrols to put more officers on foot patrol in the downtown core and inside the stores. CFS for the stores and other businesses dropped significantly.
Community Care in Bancroft had accepted a grant in exchange for supervising an individual to reside in the town who had significant mental health issues. When the Detachment Commander arrived, this individual was the source of 25 to 30 CFS each month, exhausting officers who saw this as time-consuming and repetitive, with no improvement. Local case workers were also frustrated, so the Detachment Commander did something he had never done before: he called the supervising doctor in the nearest city and asked why she was so uninvolved. She apologized, citing overwork, but agreed to visit the next day and participate in an informal Situation Table held at the Detachment and brokered by the Commander (but he did not attend). It turned out the offending individual needed constant, immediate reinforcement of positive behaviours to stay out of trouble. The local case workers made program changes and the 25 monthly CFS were almost entirely eliminated.

In both of the above examples, the falling number of CFS would result in a reduction in policing costs under the OPP billing model, so municipal leaders saw an immediate connection between reducing victimization and costs. The Detachment Commander is now an enthusiastic proponent of OMEM and can cite many other positive results in his jurisdiction.

Still, much work remains to be done. In 2014, OPP Detachment Commanders completed a survey created by the provincial Ontario Working Group (OWG) on planning for community safety and well-being, risk mitigation, community mobilization, prevention, and social development. The OPP had 100 per cent compliance in completing this survey. The results indicated that the OPP still has difficulty describing mobilization and engagement activities going on within its communities. This survey will be redone in Fall 2016 to assess improvement/increase in understanding and ability to describe/identify. by quantity, intervention, type of risk mitigated, and partners involved. The RTD will enable the identification of the most prevalent risks brought to the table, both locally by community or provincially. The RTD is a web-based application and is expected to be available in the near future.

- The OPP has received a Proceeds of Crime Grant (funds seized from criminals through a court process and redirected to community safety projects) to develop Situation Table technical guidance for communities and police. This training involves a manual written by Dr. Hugh C. Russell, one of the originators of the OMEM model, and video segments of existing tables and community of practice members speaking on topics relevant to new tables. An e-learning component has been created in partnership with Wilfrid Laurier University (WLU), Centre for Public Safety and Well-Being. This training material is now available at no cost to learners on the WLU website.

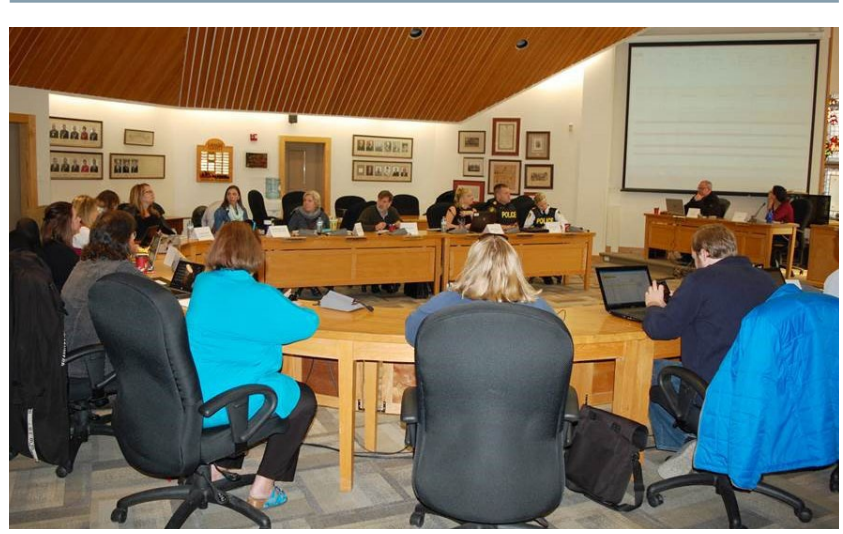

FIGURE 2 Many jurisdictions are using multi-disciplinary Situation Tables to address areas where there is acutely elevated risk to individuals, families, groups or locations 


\section{OVERCOMING EXISTING BARRIERS: LESSONS LEARNED}

Evolving towards intense collaboration with multiple service providers and community partners can be challenging for paramilitary organizations like police services. OMEM transitions have been significant for a service and sector already undergoing changes in all areas. This pace of change will be the new norm, and the OMEM model will guide the approach to community relations, interaction, and mobilization and engagement to achieve the broad reforms required in community safety and well-being. All services undergoing this process will need to be careful not to overload or burnout their frontline with demanding change.

Eventual integration of OMEM principles and actions into all programs and every corner of the organization is a key to success.

Every police service in Ontario, as well as community agencies (social services, probation and parole, etc.), is at a different stage of adopting OMEM. The OPP needs to continue to be respectful and mindful of its members and other agencies, as change is not an easy or a quick process - the basis is relationships, requiring trust and time to ensure meaningful and strong interactions though mutual understanding for long-term success.

\section{NEXT STEPS}

The OPP does not view OMEM as a starting or finishing point. The police service has already made much progress, but it recognizes there will always be work to be done. OMEM is a comprehensive model that will assist the OPP to improve its response to community safety and well-being.

The OPP wants to continue to collaborate with community partners to develop new and innovative ideas. No single service or individual can do it alone. All police services need to encourage community support because community safety and well-being in Ontario is everyone's responsibility.

\section{ACKNOWLEDGMENTS}

The author and the OPP would like to gratefully acknowledge a 2015-2016 Proceeds of Crime Grant from the Ministry of Community Safety and Correctional Services which supported: the creation of Situation Table Training materials and videos; an e-learning course hosted through Wilfrid Laurier University for use by any police agency in Ontario, community stakeholder or interested member of the public; and in-person training and consultative support to OPP detachments/community agencies as they started their own Situation Tables to develop and foster local expertise. The author would also like to acknowledge all OPP personnel who are demonstrating effective internal and external leadership by adopting and applying OMEM principles throughout the organization.

\section{CONFLICT OF INTEREST DISCLOSURES}

I have no conflicts of interest connected to the submission of this article.

\section{AUTHOR AFFILIATIONS}

*Office of the Commissioner, Ontario Provincial Police, Orillia, ON.

\section{REFERENCES}

Canadian Association of Chiefs of Police. (2016). Definitions of words and concepts that are important in promoting community safety and wellbeing. [Can be requested directly from the CACP.]

Ontario Association of Chiefs of Police. Ontario's mobilization and engagement model of community policing. (2016). Accessed April 5, 2016. Available from: http://www.oacp.on.ca/Userfiles/Files/NewAndEvents/ CrimePreventionCampaign/COMMUNITY\%2OPOLICING\%20 WHEEL-2.pdf

Ontario Provincial Police. (2016). The OPP mental health strategy: our people our communities. Accessed April 5, 2016. Available from: http://www opp.ca/index . php? \&lng=en\&id=115\&entryid=56b7al6d8f94ac0d5 c28d 175 